\title{
HEN Simulation of a Controlled Fluid Flow-Based Neural Cooling Probe Used for the Treatment of Focal and Spontaneous Epilepsy
}

\author{
Zia Mohy-Ud-Din¹, Sang Hyo Woo², Wei Qun², Jee Hyum Kim², and Jin Ho Cho', 2,+
}

\begin{abstract}
Brain disorders such as epilepsy is a condition that affects an estimated 2.7 million Americans, 50,000,000 worldwide, approximately 200,000 new cases of epilepsy are diagnosed each year. Of the major chronic medical conditions, epilepsy is among the least understood. Scientists are conducting research to determine appropriate treatments, such as the use of drugs, vagus nerve stimulation, brain stimulation, and Peltier chip-based focal cooling. However, brain stimulation and Peltier chip-based stimulation processes cannot effectively stop seizures. This paper presents simulation of a novel heat enchanger network(HEN) technique designed to stop seizures by using a neural cooling probe to stop focal and spontaneous seizures by cooling the brain. The designed probe was composed of a U-shaped tube through which cold fluid flowed in order to reduce the temperature of the brain. The simulation results demonstrated that the neural probe could cool a $7 \mathrm{~mm}^{2}$ area of the brain when the fluid was flowing atb a velocity of $0.55 \mathrm{~m} / \mathrm{s}$. It also showed that the neural cooling probe required $23 \%$ less energy to produce cooling when compared to the Peltier chip-based cooling system.
\end{abstract}

Keywords : Neural cooling probe, Fluid flow, Bio-heat transfer, Neural implant, Epilepsy.

\section{INTRODUCTION}

Many diseases are associated with the brain, such as Parkinson's disease, dystonia, chronic pain, and epilepsy. In North America, the reported epilepsy incidence is approximately 50/100,000 per year[1]. Epilepsy is a condition that is characterized by abnormal electrical activities in the brain. Many epileptics experience seizures during which they convulse, sometimes violently, before losing consciousness. These seizures are caused by an "electrical storm" of abnormal neuronal activities that spreads from the locus(or point of origin) to adjacent tissue.

Doctors are seeking different ways to cure epilepsy. It can sometimes be treated by drugs or by delivering an electrical stimulus to the brain. For electrical stimulation, electrodes are implanted into the brain. The problem with

\footnotetext{
1Department of Medical \& Biological Engineering, School of Medicine, Kyungpook National University

${ }^{2}$ School of Electrical Engineering and Computer Science, Kyungpook National Unversity

${ }^{+}$Corresponding author : jhcho@ee.knu.ac.kr (Received : Jul. 7, 2010, Revised : Jan. 4, 2011,

Accepted : Jan. 25, 2011)
}

such stimulation is that there is direct contact of the electrical circuit with the brain. The amount of stimulation required to stop epilepsy is still unknown. Its treatment effect is limited to decreasing electrical activity in the brain[2]. In epilepsy, brain temperature is raised above normal temperature. The electrical stimulus also causes a rise in temperature that can produce health hazards in the epileptic condition[3], so there is still a need to find an effective method to stop epileptic seizures. Since the discovery that all electrical activity of the brain stops when its temperature decreases below $20^{\circ} \mathrm{C}[4]$, scientists have been attempting to find effective ways to cure epilepsy by creating a hypothermic condition in the brain.

L. Zhu et al. described a simulation of a method to treat brain injury using hypothermia[5]. They reduced the temperature of the head to $0{ }^{\circ} \mathrm{C}$ to determine whether the brain can be cooled in this way. The drawbacks of the system are that thermal energy could not reach below 17 $\mathrm{mm}$ of brain depth, it only stop epileptic seizures on the upper surface of the brain. Ice packs were used outside the brain, which occupied a large amount of space and could not be used as a portable system. They did not mention the amount of heat dissipation required to cure epilepsy.

G. Reynaldo et al. described a heat transfer model 
designed to simulate a focal cooling process to suppress spontaneous epilepsy activities[6]. An inconvenient aspect of the system was that it consumed approximately $-13,000$ Joules in order to reduce the temperature below $24^{\circ} \mathrm{C}$. No mention was made of which type of cooling sensors had been used to achieve this target.

Yang et al. and H. Imoto et al. implemented a systems designed to terminate the neocortical seizure process using focal cooling in rats[7,8]. They placed a Peltier sensor on the brain after performing a craniotomy. They illustrated that the brain cooling process was an effective method to completely stop a seizure within 5 seconds. Yang's system was rather large, utilizing a $7 \mathrm{~mm}$ x $7 \mathrm{~mm}$ Peltier sensor. The sensor cannot be implanted into the brain, and the system lacked a heat sink. The H. Imoto et al. system was the size of the Peltier sensor $(9 \mathrm{~mm} \times 6.5 \mathrm{~mm})$, and the sensor also could not be implanted into the brain. They placed cold water on the back of the Peltier sensor as a heat sink and held the water at a constant temperature of $37^{\circ} \mathrm{C}$.

This paper describes the simulation of a controlled water flow-based neural cooling probe used to stop focal and spontaneous(depending on the probe placement) seizures in any area of the brain. The neural cooling probe was composed of a U-shaped tube through which cold water would flow in order to reduce brain temperature. The simulation results demonstrated that a neural probe could effectively control focal and spontaneous epilepsy.

\section{DESIGN}

\section{1 Basic principles of the controlled fluid flow- based neural cooling probe}

Fig. 1 illustrates the block diagram of the neural cooling probe. The probe was assumed to be positioned in the epileptic area of the brain. As the seizure occurred, the neural probe would decrease the temperature around the probe. The neural probe was a parabolically shaped structure, and water flowed through it. The water inside the neural probe was $10^{\circ} \mathrm{C}$. A Peltier sensor was placed outside the brain in order to maintain the temperature of the water. A liquid pump was placed outside of the brain in order to control the water flow. The main objective of the investigation was to control the cooling of an area of the brain by controlling both the amount as well as the flowrate of water in the tube.

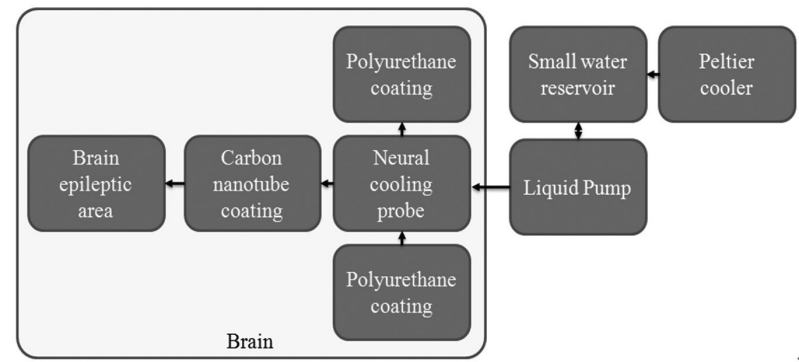

Fig. 1. Basic concept of the controlled fluid flow-based neural cooling probe.

\section{2 Mathematical formulation of heat transfer}

Unlike a pure conductive medium, the heat transport process in brain tissues is difficult to model, because the convective effects of blood flow are not readily assessed. Blood vessels are present in such a large number, and have such a complicated geometry, that it was not practical to develop a comprehensive model that included the effects of all thermally significant vessels in the tissue. Existing models of heat transport in tissues include continuum models, in which heat and mass transport effects are averaged over the representative control volume.

One of the widely used continuum models was proposed by Pennes[9] and was calculated as

$\rho c \frac{\partial T}{\partial x}=\Delta k_{t} \cdot \Delta T+\rho c \omega\left(T_{a}-T\right)+q_{m}+P$

where $k_{t}, \rho, c, \omega, T_{a}, T, q_{m}$, and $P$ represented the thermal conductivity of tissue, blood density, specific heat of blood, local blood perfusion rate, temperature of the arteries, temperature of the brain at any particular instant, local metabolic heat generation rate, and energy dissipation, respectively. This equation was originally a modified form of the partial differential equation of heat conduction. Many scientists have questioned the validity of the Pennes equation since 1980, but it has been successfully applied to bio-heat transfer analysis as an analytical tool. This equation was also used in the analysis of brain hypothermia as well as temperature distributions within the brain. Some scientists have used this equation for obtaining polar coordinates, which could also be derived from the heat equation in cylindrical coordinates. The heat equation in one-dimensional cylindrical coordinates is[10] : 


$$
\frac{d^{2} T}{d r^{2}}+\frac{1}{r} \frac{d T}{d x}+\frac{q}{k}=0
$$

where $r$ and $k$ represent radius and thermal conductivity of material, respectively. In this simulation, the brain was modeled as a hemisphere of cerebral tissue with uniform thickness; the parameters used in the simulation are exhibited in Table 1. By combining the Pennes heat equation and the one-dimensional spherical heat equation, the modified bio heat transfer equation becomes as follows

$$
\frac{d^{2} T}{d r^{2}}+\frac{1}{r} \frac{d T}{d x}+\rho_{b} w_{b} c_{b}\left(T_{a}-T\right)+\frac{q_{m}}{k_{\text {braain }}}+P=0
$$

\begin{tabular}{|c|c|c|}
\hline Parameter (units) & Name, Symbol & Value \\
\hline \multirow{2}{*}{$\begin{array}{l}\text { Specific Heat } \\
\left(\mathrm{W} \mathrm{kg}^{-1} \mathrm{~K}^{-1}\right)\end{array}$} & Blood, $c_{b}$ & 3800 \\
\hline & Brain tissue, $c_{b t}$ & 3700 \\
\hline $\begin{array}{l}\text { Male brain Volume } \\
\qquad(\mathrm{ml})\end{array}$ & Brain, V & 1200 \\
\hline $\begin{array}{l}\text { Mass density } \\
\left(\mathrm{kgm}^{-3}\right)\end{array}$ & Blood, $\rho_{b}$ & 1050 \\
\hline $\begin{array}{l}\text { Thermal Conductivity } \\
\left(\mathrm{W} \mathrm{mK}^{-1}\right)\end{array}$ & Brain tissue, $k_{\text {brain }}$ & 0.50 \\
\hline $\begin{array}{c}\text { Perfusion rate } \\
\left(\mathrm{ml} 100 \mathrm{~g}^{-1} \mathrm{~min}^{-1}\right)\end{array}$ & Brain tissue, $\omega_{b}$ & 50 \\
\hline $\begin{array}{c}\text { Metabolic heat } \\
\text { generation rate }\left(\mathrm{Wm}^{-3}\right)\end{array}$ & Brain tissue, $q_{m}$ & 10437 \\
\hline Thickness, adult (mm) & Brain tissue, $r$ & 83 \\
\hline $\begin{array}{l}\text { Mass density } \\
\left(\mathrm{kgm}^{-3}\right)\end{array}$ & Water, $\rho$ & 1000 \\
\hline $\begin{array}{c}\text { Area of neural cooling } \\
\text { probe }\left(\mathrm{m}^{2}\right)\end{array}$ & Neural cooling probe, $\mathrm{A}$ & 0.00016 \\
\hline $\begin{array}{l}\text { Coefficient of parabola } \\
\text { cure of neural probe, (a) }\end{array}$ & Equation of parabola, Y & $\begin{array}{c}\mathrm{Y}=0.32 \mathrm{x}^{2+} \\
3.1 * 10^{-16}\end{array}$ \\
\hline Length (mm) & Brain length, $L$ & 165 \\
\hline $\begin{array}{l}\text { Rigid expanded } \\
\text { polyurethane board } \\
\left(\mathrm{W} \mathrm{m}^{-10} \mathrm{C}^{-1}\right)\end{array}$ & Neural Probe Coating, Co & 0.021 \\
\hline Specific heat (g) & Water, $c$ & 4.2 \\
\hline
\end{tabular}

Table 1. Parameters used in the simulation process

Based on the above table, we acquire the value of $q_{m}$ (local metabolic heat generation rate) for the entire brain. We required local metabolic heat generation at a particular radius in the brain for the simulation process. The metabolism of a 1-mm area of the brain was approximately $125 \mathrm{~W} / \mathrm{m}^{2}$. We could therefore calculate the local metabolic heat generation process for a particular radius of the brain. By using equation 3, we calculated the temperature changes at a particular radius of the brain. In order to counter the metabolic heat of the brain, we injected a particular amount of cooled water into the brain with the neural probe. The boundary conditions which were applied to the brain simulation process were a constant brain temperature of $37^{\circ} \mathrm{C}$ at the outer layer of the brain, and a temperature of $10^{\circ} \mathrm{C}$ at the position of the neural cooling probe.

\section{3 Design and controlled fluid flow simulation in the neural cooling probe}

The neural probe was a silicon tube which was bent in the center to form a $U$ shape. The diameter of the tube was $3.5 \mathrm{~mm}$ and its length was $10 \mathrm{~cm}$. Cooled water was channeled through the tube in order to produce a cooling effect. The tube was covered with rigid expanded polyurethane in order to prevent heat loss. The parabolic area of the tube was covered with carbon nanotubes to provide an excellent heat transfer rate and provide biocompatibility between the probe and the targeted brain area. By coating with carbon nanotubes, we reduced fibrosis around the neural cooling probe.

A micro pump was placed behind the tube in order to control the flow of the water from tube, as shown in Fig. 2. The other end of the pump was connected to a squareshaped packet. The pack was used as a reservoir of water. The dimensions of the pack were $2 \mathrm{~cm} \times 2 \mathrm{~cm}$. A Peltier sensor was placed on the pack in order to maintain the water temperature at a constant $10^{\circ} \mathrm{C}$.

For the simulation of the controlled fluid flow, we used the equation for the mass flow rate in a tube structure, as follows[11]:

$$
\mathrm{m}=\rho \cdot \nu \cdot A
$$

where $\mathrm{m}$ represents the mass flow rate, $\rho$ represents the density of water, $A$ and represents the flow area. The area was calculated using the formula for a parabola because the neural probe had a parabolic shape. The coefficients of the parabola are shown in Table 1. The calculated area of the tube is $0.00016 \mathrm{~m}^{2}$. The density of the water is also constant, so by changing the velocity of the fluid, we could control the mass flow rate. 


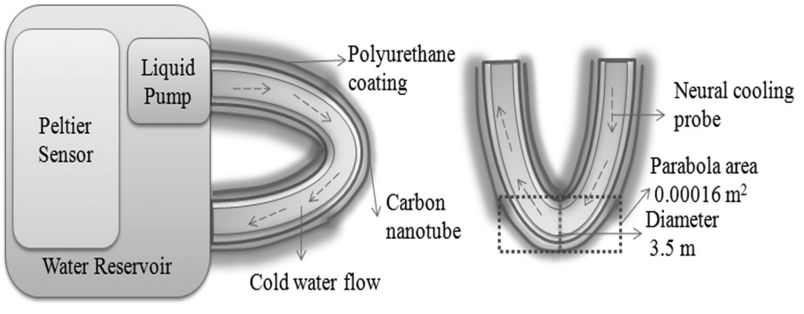

Fig. 2. Design of the controlled fluid flow-based neural cooling probe: (a) system design; (b) neural probe area and diameter

In order to calculate energy dissipation from the electrode to the brain, we used the following formula[12]:

$$
\mathrm{Q}=C \cdot M \cdot \Delta T
$$

in which Q represents heat dissipation, $C$ represents the specific heat capacity, and $\Delta T$ symbolizes the change in temperature. Using equations 4 and 5 , we calculated the energy dissipation from the neural probe when water was flowing through it at a particular velocity.

\section{RESULT AND DISCUSSION}

Two types of simulations were carried out in order to illustrate the effectiveness of the neural cooling probe: 1) when the probe was placed at the bottom surface of the brain, as shown in Fig. 3(a); 2) when the probe was placed $30 \mathrm{~mm}$ above the center of the brain, as shown in Fig. 3(b).

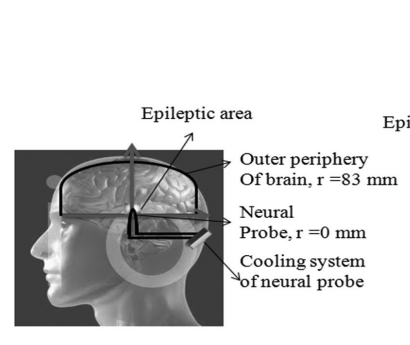

(a)

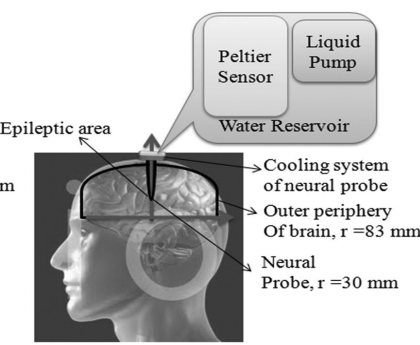

(b)
Fig. 3. Placement of the neural cooling probe to produce cooling: (a) when the probe was placed at radius zero; (b) when the probe was placed at radius $30 \mathrm{~mm}$

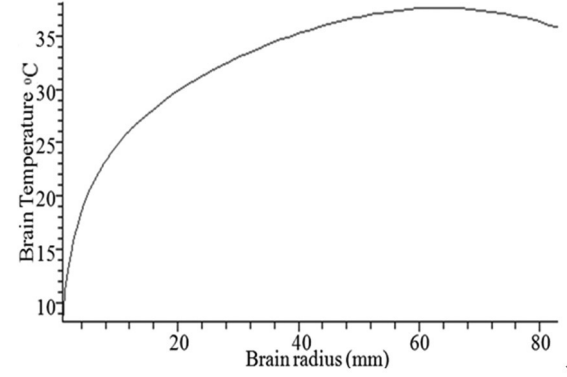

Fig. 4. Brain temperatures at different brain radii.

\subsection{When the neural cooling probe was placed at the bottom of the brain}

In the first simulation, the temperature at the outer periphery(radius $83 \mathrm{~mm}$ ) started at $37^{\circ} \mathrm{C}$. The temperature at the bottom(radius zero) of the brain was $10{ }^{\circ} \mathrm{C}$ because the neural cooling probe had caused the temperature to decline. Fig. 4 illustrates the changes in brain temperature when the neural probe was placed at the bottom of the $\operatorname{brain}(\mathrm{r}=0)$. The water was flowing through the probe at a velocity of $0.55 \mathrm{~m} / \mathrm{s}$. The amount of heat dissipated by the probe into the brain was about -10000 Joules.

Fig. 4 shows that approximately $7 \mathrm{~mm}^{2}$ area of the brain could be cooled below the $20{ }^{\circ} \mathrm{C}$ by placing the probe at the bottom of the brain. Table 2 illustrates the increases in the area of the brain effectively cooled by increasing the velocity of the fluid from the probe. This was due to the fact that an increase in the velocity of the mass flow rate caused a greater amount of heat dissipation in the brain.

Table 2. Changes in fluid velocity and corresponding changes in the brain cooled region

\begin{tabular}{c|c|c}
\hline $\begin{array}{c}\text { Velocity of the } \\
\text { fluid }(\nu)\end{array}$ & $\begin{array}{c}\text { Heat dissipation } \\
(\mathrm{P})\end{array}$ & $\begin{array}{c}\text { Brain area } \\
\text { effectively cooled }\end{array}$ \\
\hline $0.27 \mathrm{~m} / \mathrm{s}$ & 5000 Joules & $4 \mathrm{~mm}^{2}$ \\
\hline $0.55 \mathrm{~m} / \mathrm{s}$ & 10000 Joules & $7 \mathrm{~mm}^{2}$ \\
\hline $0.82 \mathrm{~m} / \mathrm{s}$ & 15000 Joules & $9.5 \mathrm{~mm}^{2}$ \\
\hline $1.06 \mathrm{~m} / \mathrm{s}$ & 20000 Joules & $18 \mathrm{~mm}^{2}$ \\
\hline
\end{tabular}

\section{2 When the neural cooling probe was placed at distance 30 from origin of the brain}

In the second simulation, the temperature of the outer periphery and the bottom of the brain started at $37^{\circ} \mathrm{C}$. The temperature was $10^{\circ} \mathrm{C}$ at the $30-\mathrm{mm}$ radius due to the neural probe placement. 


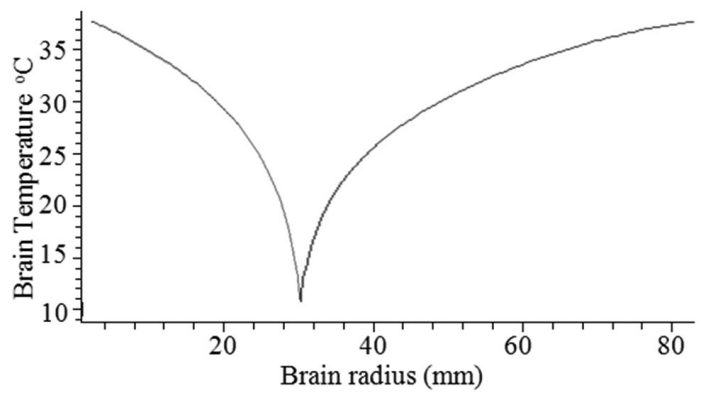

Fig. 5. Brian temperature changes according to Brain radius.

Fig. 5 illustrates the changes in brain temperature according to the distance from the brain's center. When the heat dissipation was $-10,000$ joule and the fluid flow velocity was $0.55 \mathrm{~m} / \mathrm{s}$, an area of about $8 \mathrm{~mm}^{2}$ of the brain was observed to have been effectively cooled to below 20 ${ }^{\circ} \mathrm{C}$. Previous methods use to reduce the temperature of the brain consume $-13,000$ joule energy to reduce the temperature of the brain such as G. Reynaldo et al. had done. The presented system is required $23 \%$ less energy than the previous method. In this way, we could treat epilepsy at any part of the brain by placing the probe at a particular position in order to cool the brain below $20^{\circ} \mathrm{C}$.

\section{CONCLUSION}

This novel method may effectively treat epilepsy within any area of the brain. The shortcomings of the electrical stimulation method, such as the direct contact of the brain with an electrical circuit and the thermal effect of the electrical stimulus, could be overcome by the neural cooling probe. Despite its size, the Peltier chip-based cooling system could not produce a deep brain cooling effect, and its poor heat sink could be replaced by a neural cooling probe. The neural cooling probe system is relatively small $(7 \mathrm{~mm} \times 3.5 \mathrm{~mm})$ and could produce cooling in the deep brain, which illustrates its superior effectiveness when compared with the Peltier chip-based cooling system. It utilized $-10,000$ Joules, which was 23 $\%$ less energy than that utilized by the focal cooling approach. Further studies are being conducted to determine the proper materials for heat insulation, as well as to reduce the size of the neural probe as much as possible.

\section{ACKNOWLWEDGMENTS}

This work was supported by Grant no. 10031779 from the Strategic Technology Development Program of Ministry of Knowledge Economy. Also, this work was supported by the Grant of the Korean Ministry of Education, Science and Technology(The Regional Core Research Program/Anti-aging and Well-being Research Center). This work was supported by the Brain Korea 21 Project. This work was also supported by grant of the Oriental Medicine R\&D Project, Ministry of Health, Welfare and Family Affairs, Republic of Korea(B080033), the Korean Science and Engineering Foundation(R012007-000-2056-0), the Korean Research Foundation, Next generation leading tech. grant(Daegu, EQMed).

\section{REFERENCES}

[1] http://www.ilae.org/Visitors/Chapters/documents/ usa.pdf.

[2] W. C. Stacey, and B. Litt, "Technology insight: neuroengineering and epilepsy designing devices for seizure control," Nature Clinical Practice Neurology, vol. 4, no. 4, pp. 190-201, 2008.

[3] M. M. Elwassif, Q. Kong, M. Vazquez, and M. Bikson, "Bio-heat transfer model of deep brain stimulation induced temperature changes," Journal of neural engineering, vol. 3, no. 4, pp. 306-315, 2006.

[4] V. A. Sosenkov, and V. D. Chirkov, "Electrical activity of neurons in the cat cortex during cooling," Neirofiziologiya, vol. 2, no. 1, pp. 59-63, 1970.

[5] L. Zhu, and C. Diao, "Theoretical simulation of temperature distribution in the brain during mild hypothermia treatment for brain injury," Medical and biological engineering \& computing, vol. 39, pp. 681687, 2001.

[6] G. Reybaldo, D. Rafael, G. Paul, R. Boris, and B. Mitchel, "Heat transfer model of characterize the focal cooling necessary to suppress spontaneous epileptiform activity," Thermal Treatment of Tissue: Energy Delivery and Assessment, vol. 5698, pp. 240-246, 2005.

[7] X. F. Yang, and S. M. Rothman, "Focal cooling rapidly terminates experimental neocortical seizures," Annals of Neurology, vol. 49, no. 6, 2001.

[8] H. Imoto, M. Fujii, J. Uchiyama, H, Frjisawa, K. Nakano, I. Kunitsuga, S. Nomura, T. Saito, and M. Suzuki, "Use of a peltier chip with a newly devised 
local brain cooling system for neocortical seizures in the rat," Journal of Neurosurgery, vol. 104, 2006.

[9] S. Maemosono, and S. Saita, "Theoretical assessment of $\mathrm{FePt}$ nanoparticles as heating elements for magnetic hyperthermia," IEEE Transactions on Magnetics, vol. 42, no. 6, pp. 1638-1642, 2006.
[10] K. D. Hagen, "Heat transfer with applications," Prentice Hall, 1999.

[11] http://en.wikipedia.org/wiki/Mass flow rate

[12] http://www.leaningpinesoftware.com/hot_water pipes_Newtons_cooling.shtml.

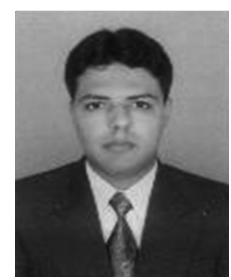

Zia Mohy-Ud-Din received his BS degree in Biomedical Engineering from Sir Syed University, Pakistanin 2005, and received M.S degree from Medical \& Biological Engineering department, Kyungpook National University, Korea in 2008. He is currently a Ph.D candidate in Medical \& Biological Engineering department at Kyungpook National University in Korea. His research interests include BCI for emotion detection, biotele-metry, neural engineering, and neural stimulation.

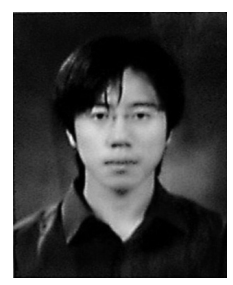

Wei Qun received his B.S. and M.S. degrees in Electrical Engineering from Kyungpook National University, Korea in 2008 and 2010. He is Ph.D candidate in Electrical Engineeing at Kyungpook National University in Korea. His research interests include sensor application and neural engineering.

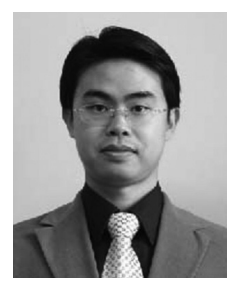

Jee-Hyun Kim received his $\mathrm{Ph}$. D. degree from university of Taxes Austin. He is currently a professor in the school of electrical engineering and computer science department. His research interests are Optical imaging, optical instrumentation and neural engineering.

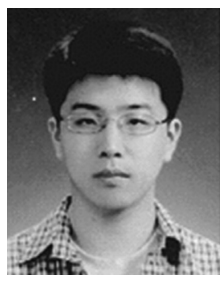

Sang-Hyo Woo received his B.S, M.S and Ph.D degrees in Electrical Engineering from Kyungpook National University, Korea in 2004 and 2006, 2011 respectively.His research interests include telemetry system based on the capsule endoscope. Especially, electrical stimulus and measuring peristalsis movement of the small intestine.

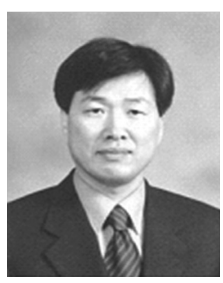

Jin-Ho Cho received his Ph. D. degree from Kyungpook National University in 1988. He was a visiting professor in dept. of Biomedical engineering, College of Engineering at University of Iowa, USA, in 1991. He is Professor in the school of Electrical Engineering, College of IT Engineering, Kyungpook National University, a vice chairman of at the Korea Society of Medical Biological Engineering, a Director of the Advanced Research Center of Recovery of Human Sensibility. His research interests include the biomedical signal processing, sensor applications, and biomedical instrumentations. He is a Member of the IEEE. 